\title{
AUDIÊNCIAS PÚBLICAS AMBIENTAIS E RACIONALIDADE AMBIENTAL: PERSPECTIVAS E DESAFIOS
}

\author{
E. A C. Pegado ${ }^{1,2}$ e E. M. Barbosa ${ }^{2}$ \\ ${ }^{1,2}$ Instituto Federal de Educação Ciência e Tecnologia do Rio Grande do Norte \\ ${ }^{2}$ PPG em Recursos Naturais - Universidade Federal de Campina Grande \\ erika.pegado@ifrn.edu.br ${ }^{1}$, erifat@terra.com.br ${ }^{2}$
}

Artigo submetido em dezembro/2012 e aceito em fevereiro/2013

\section{RESUMO}

A Constituição Federal Brasileira traz, em seu bojo, princípios explícitos que garantem o exercício da democracia direta. Dentre os diversos princípios básicos nela presentes, destacam-se o da responsabilização compartilhada e o da participação popular, que se aproximam de conceitos revolucionários, como o da racionalidade ambiental. O presente artigo apresenta uma breve análise, sob o viés da racionalidade ambiental, das perspectivas e dos limites do exercício da cidadania ambiental nas audiências públicas ambientais, com base no princípios da responsabilização compartilhada e da participação popular, refletidos nas audiências públicas integrantes dos processos de licenciamento ambiental para atividades petrolíferas na região de Macau, no estado do Rio Grande do Norte, Brasil, a partir da visão de um grupo de atores sociais participantes. A metodologia, na fase exploratória, foi a pesquisa bibliográfica e documental e, posteriormente, para coleta de dados sobre a percepção do grupo de atores sociais, utilizou-se a técnica do grupo focal. Concluiu-se que, apesar de o aparato normativo ambiental brasileiro ser considerado de excelente qualidade, na prática as audiências públicas ambientais carecem de aperfeiçoamento, principalmente no que diz respeito à oitiva da população e à resposta às considerações expostas pela comunidade nesses importantes espaços democráticos.

PALAVRAS-CHAVE: Gestão ambiental, princípio da responsabilização compartilhada, princípio da participação popular, racionalidade ambiental, audiência pública ambiental.

\section{ENVIRONMENTAL PUBLIC HEARINGS AND ENVIRONMENTAL RATIONALITY: PROSPECTS AND CHALLENGES}

\section{ABSTRACT}

The Brazilian Constitution brings in its wake, explicit principles that guarantee the exercise of direct democracy. Among the many basic principles it presents, we highlight the shared accountability and popular participation, approaching revolutionary concepts such as environmental rationality. This article presents a brief analysis under the bias of environmental rationality, the prospects and limits of environmental citizenship in environmental public hearings, based on principles of shared accountability and popular participation, reflected in public hearings integral to the process of environmental licensing for oil activities in the Macau region, in the state of Rio Grande do Norte,
Brazil, from the vision of a group of social actors participating. The methodology in the exploratory phase was research literature and documents and subsequently to collect data on the perception of the group of social actors, used the focus group technique. It was concluded that, although the Brazilian environmental regulatory apparatus be considered of excellent quality, in practice the lack of public hearings environmental improvement, especially with regard to hearsay population and the response to the foregoing by the community in these important democratic spaces.

KEY-WORDS: Environmental management, principle of shared responsibility, the principle of popular participation, environmental rationality, environmental public hearing. 
AUDIÊNCIAS PÚBLICAS AMBIENTAIS E RACIONALIDADE AMBIENTAL: PERSPECTIVAS E DESAFIOS

\section{INTRODUÇÃO}

$\mathrm{Na}$ busca do desenvolvimento sustentável, o direito é um importante instrumento de gestão pública ambiental, no caso das sociedades democráticas, que possibilitam a atuação estatal com o braço forte da lei. A Administração Pública, se voltada para a sustentabilidade ambiental, se baseia em parâmetros jurídicos que contemplam aspectos coletivos em consonância com os princípios gerais do direito ambiental, alicerce da disciplina jurídica.

Nesse contexto, a Constituição Federal traz, em seu bojo, princípios explícitos que garantem o exercício da democracia direta, dotados de positividade, portanto, devendo ser levados em conta pelo aplicador da ordem jurídica em todas as esferas de poder, como frisa Antunes (2005 p.16). Dentre esses, destacam-se o da responsabilização compartilhada e o da participação popular, que se aproximam de conceitos revolucionários, como o da racionalidade ambiental, cunhado por Leff (2006).

A normatização ambiental brasileira também fornece subsídios para a busca do ideal de desenvolvimento socialmente includente, economicamente sustentado e que contemple aspectos ambientais, sociais e econômicos, preconizado por Sachs (2008). Porém, apesar de o aparato normativo ambiental ser considerado de excelente qualidade, comprometido com os ideais democráticos ambientais, com inspiração em documentos internacionais, como o Relatório Brundtland, de 1987, e a Carta da Terra, de 1992, o exercício da cidadania, na realidade brasileira, ainda reflete a inexperiência de parte da população no trato dos instrumentos democráticos de participação direta.

Um exemplo dessa situação ocorre nas audiências públicas ambientais, obrigatórias no processo de licenciamento ambiental para atividades de relevante impacto ao meio ambiente, tema deste trabalho. As dificuldades relatadas no procedimento refletem deficiências históricas, fruto de uma de uma nação de contrastes, com baixos índices de desenvolvimento humano em diversas regiões. A pujança econômica desta que é uma das maiores economias do mundo da primeira década do século XXI ainda não se refletiu nos Índices de Desenvolvimento Humano.

O presente artigo tem como objetivo fazer uma breve análise, a partir da ótica da racionalidade ambiental, sobre as perspectivas e os limites práticos das audiências públicas ambientais, com base nos princípios da responsabilização compartilhada e da participação popular, refletidos nas audiências públicas que ocorrem nos processos de licenciamento ambiental para atividades petrolíferas, que geram significativo impacto ao meio ambiente. Apresenta-se, ao final, a visão de um grupo de atores sociais que já participaram de audiências públicas sobre o tema.

\section{METODOLOGIA}

Utilizou-se, neste estudo, a pesquisa bibliográfica e a documental, além da técnica de grupo focal, que possibilita ao pesquisador, através de um diálogo direcionado para um tema específico, coletar dados sobre a percepção de um grupo de atores sociais, permitindo que, através de um ambiente de interação entre o grupo e o entrevistador, os participantes respondam em conjunto, refletindo assim as ideias do grupo. Essa técnica de discussão deve ocorrer em reuniões com pequeno número de informantes, com a presença de um facilitador que intervém, em momentos oportunos, como forma de focalizar e aprofundar a discussão 
(MINAYO, 2004).

Contribuíram para este estudo um grupo formado por seis informantes, integrantes da Comissão de Justiça e Paz de Macau, estado do Rio Grande do Norte, situada na comunidade de Diogo Lopes. A maioria são pescadores com mais de 10 anos de ofício, legitimados para participar das audiências públicas referentes ao processo de licenciamento ambiental da atividade petrolífera na área rural do município. A Comissão de Justiça e Paz de Macau é uma organização bastante atuante, com histórico de atuação na luta que resultou na criação da Reserva de Desenvolvimento Sustentável da Ponta do Tubarão.

A entrevista com o grupo ocorreu na sede da Comissão, no distrito de Diogo Lopes, área rural do município de Macau. A temática abordada foi a participação do grupo nas audiências públicas referentes à atividade petrolífera ocorrida, no município, nos último 05 (cinco) anos.

Os participantes foram convidados pela entrevistadora a refletir sobre a importância das audiências públicas e a da sua participação nelas. As perguntas abertas eram dirigidas ao grupo e os respondentes comentavam sobre suas impressões por ocasião das audiências públicas, tanto como indivíduos quanto participantes do grupo. Ao final de cada rodada de respostas dos integrantes, as impressões coletivas colhidas eram alinhadas e referendadas pelo grupo para que se chegasse a um consenso.

\section{OS PRINCÍPIOS JURÍDICOS DA RESPONSABILIZAÇÃO COMPARTILHADA E DA PARTICIPAÇÃO POPULAR}

A preservação do meio ambiente constitui-se num desafio reiterado, pois a centralização administrativa ainda é uma tônica, não obstante o fato de a gestão compartilhada ser apontada como a forma mais adequada de preservar o meio ambiente. Apesar de a Constituição Federal Brasileira impor ao poder público e à coletividade o dever de preservar o meio ambiente ecologicamente equilibrado, sendo este, de acordo com Fiorillo, Morita e Ferreira (2011), um aspecto fundamental quanto ao conteúdo do art. 225 da Carta Magna, o exercício desse aspecto da cidadania ainda é incipiente no Brasil, embora haja avanços recentes.

Não obstante as variadas conjunturas políticas e sociais do país, a divisão de responsabilidades, na gestão ambiental, entre administração pública, empresariado e cidadãos interessados, no Brasil, tem origem normativa e principiológica, refletindo os ideais do Estado Democrático de Direito.

Dentre os princípios garantidores da ordem democrática ambiental, destaca-se o princípio da responsabilização compartilhada, que vincula, em igual medida, o Estado e a coletividade ao dever de defender e preservar o meio ambiente. Esse princípio, presente em diversas constituições contemporâneas, decorre da evolução do conceito de administração pública, a partir do reconhecimento da incapacidade funcional das instâncias públicas em proporcionar os níveis de proteção ambiental requeridos pela sociedade. Assim, a função de proteger o meio ambiente tende a ser compartilhada com outras instâncias, mediante a atribuição e o exercício de direitos fundamentais, que não podem ser garantidos sob uma lógica estritamente estatal, a qual pode ser fruto de decisões eivadas de insuficiência técnica ou estrutural (AYALA, 2011).

Assim, esse princípio está vinculado a outro, de fundamental importância: o da participação popular, evidenciado quando, por ocasião das audiências públicas ambientais, os representantes da comunidade que será potencialmente atingida pelos impactos de um empreendimento têm o direito de expor suas posições e seus argumentos em relação ao processo de licenciamento ambiental. E esses argumentos deverão ser levados em consideração 
pela administração pública, interferindo, inclusive, na decisão de autorizar ou não a instalação do empreendimento que requer a licença ambiental.

O princípio jurídico da participação popular garante ao cidadão interessado o direito à informação, por parte de órgãos públicos, sobre os aspectos ambientais do empreendimento, mesmo durante a fase de análise dos estudos ambientais. Ressalta-se que esse direito não obsta à garantia dada à sociedade civil organizada, e ao cidadão em particular, de se valerem de mecanismos judiciais e administrativos de controle dos atos praticados pela Administração Pública, tais como ações populares e ações civis públicas.

Essas garantias decorrem da própria Constituição Federal Brasileira de 1988 que considera todos responsáveis pelo meio ambiente, em alguma medida, e a proteção deste é função não apenas do Estado, em todas as suas esferas, mas também, e principalmente, de cada um dos membros da coletividade. (AYALA, 2011)

A participação do cidadão nas decisões de poder surge como uma das principais características de um estado democrático, pois, de maneira mais extensiva, aplica-se ao direito que tem o cidadão, organizado ou não, de intervir - porque parte interessada - no procedimento de tomada da decisão ambiental. (MILARÉ e BEJAMIM, 1993)

A Carta Magna veio consolidar o entendimento já pacificado por aqueles que lutavam pela proteção ambiental: a proteção ao meio ambiente, para realmente ser efetivada, só será possível com a participação de todos os cidadãos de forma organizada e consciente. Porém essa participação sofre influências diversas, dentre as quais o grau de interesse econômico e o nível de organização política de determinada comunidade. E esse grau de cidadania influencia na construção da racionalidade ambiental, a seguir comentada.

\section{RACIONALIDADE AMBIENTAL: UM CAMINHO PARA A SUSTENTABILIDADE}

Como conceito revolucionário, a racionalidade ambiental não consiste na expressão de uma lógica da natureza, do mercado, de uma lei ou valor, mas é um constructo de normas, interesses, valores, significações e ações que vão além dos processos sociais e suas atuais estruturas. Em outras palavras:

A categoria de racionalidade ambiental possibilita uma análise integrada das bases materiais, os instrumentos técnicos e legais e as ações e programas orientados para este fim. Neste sentido a categoria de racionalidade ambiental é proposta como um conceito heurístico, dinâmico e flexível para analisar e orientar os processos e as ações "ambientalistas". (LEFF , 2007 p. 127)

A racionalidade ambiental deve ser entendida como um conjunto de objetivos, meios, instrumentos, regras sociais, normas jurídicas, valores culturais, dentre outros aspectos, que legitimam ações e estabelecem critérios para tomadas de decisão de agentes sociais, orientando políticas de governos e normatizando os processos de produção e consumo, para, enfim, conduzir ações e comportamentos de diversos atores e grupos sociais para a consecução de desenvolvimentos sustentável, equitativo e duradouro. (LEFF,2007)

A construção da racionalidade ambiental é necessária para o novo milênio, assim como os processos sociais que garantem a participação da sociedade na gestão dos recursos naturais. Constituem garantias conquistadas após anos de aprendizado democrático. Para isso são necessárias: uma reorganização transversal da ciência e da administração pública; a formação de uma ética ambiental; a construção de um novo saber, que, além de sua relação de objetividade com o mundo, se dá em sua relação com o ser, requerendo a intervenção de um conjunto de 
processos sociais, inclusive a reforma democrática do Estado, com vistas a canalizar a participação da sociedade na gestão dos recursos. (LEFF,2006)

Esse novo saber requer a prática da interdisciplinaridade, que se constitui em uma interrelação de processos, conhecimentos e práticas que vão além do campo da pesquisa e do ensino, sendo uma busca de colaboração dos diversos campos do saber e incluindo práticas nãocientíficas, num diálogo de saberes que atenta para outras formas de conhecimento, como, por exemplo, o conhecimento tradicional dos moradores do entorno.

Partindo-se dessas premissas, defende-se a ideia de que os estudos ambientais levem em consideração a construção da racionalidade ambiental, com a inclusão dos saberes tradicionais da população do entorno dos empreendimentos de relevante impacto ambiental a serem licenciados, que será diretamente atingida pelos impactos das atividades de tais empreendimentos.

Essa população, legitimada pela norma jurídica e pelos princípios anteriormente comentados, tem o direito de expressar a opinião, sobre as conclusões constantes no Relatório de Impacto do Meio ambiente - RIMA - que deve ser levada em consideração pela Administração Pública nas etapas do processo de licenciamento ambiental, principalmente na elaboração dos estudos ambientais e nas audiências públicas.

$\mathrm{Na}$ realidade atual brasileira, porém, como exposto a seguir, ainda há muito a caminhar nesse sentido.

\section{AUDIÊNCIAS PÚBLICAS AMBIENTAIS E SUAS LIMITAÇÕES}

As audiências públicas ambientais integram os processos de licenciamento ambiental que tratam da autorização de empreendimentos considerados de elevado potencial de impacto ambiental. Nelas deve ser apresentado à comunidade o RIMA, que reflete os resultados do Estudo de Impacto Ambiental (EIA).

O EIA é exigido nas atividades que causem ou possam causar impactos significativos, de acordo com a Resolução CONAMA 01, de 1986, que estabelece uma lista de empreendimentos que devem apresentar esse estudo ambiental mais completo. Porém o rol é exemplificativo, cabendo ao órgão licenciador ou ao Ministério Público decidir sobre a aplicação do EIA/RIMA, de acordo com a complexidade do projeto. (GRANZIERA, 2009)

A Constituição Federal de 1988 consolida em seara constitucional esse primado legal no § 10 do Art. 225:

$\S 1$ 으 - Para assegurar a efetividade desse direito, incumbe ao Poder Público:

[...]

IV - exigir, na forma da lei, para instalação de obra ou atividade potencialmente causadora de significativa degradação do meio ambiente, estudo prévio de impacto ambiental, a que se dará publicidade; (BRASIL, 1988)

Diversos países adotam o Estudo de Impacto Ambiental como um dos principais instrumentos públicos de gestão ambiental. A evolução do procedimento remonta ao final do século XX, com obrigatoriedade da Avaliação de Impacto Ambiental (AIA), nos Estados Unidos da América. A origem da AIA encontra-se na Nacional Evironmental Policy Act (NEPA), a lei que estabeleceu a Política Nacional Ambiental nos Estados Unidos, aprovada em 1969 pelo Congresso Nacional. Essa pioneira lei americana serve de modelo para legislações ambientais em 
todo o mundo. A norma estadunidense exige uma declaração equivalente a um estudo de impacto ambiental para iniciativas do governo federal que possam causar modificações ambientais, incluindo aí todas as Agências Federais e os projetos privados que precisem de aprovação federal, como os de mineração, as usinas nucleares, hidrelétricas, etc. (SÁNCHEZ, 2006)

O Estudo de Impacto Ambiental, modalidade mais completa dos estudos ambientais, deve ser elaborado por uma equipe multidisciplinar, envolvendo profissionais dos diversos ramos do saber, devidamente cadastrados nos órgãos ambientais, e serve como base para a análise do pedido de licença ambiental, de acordo com a própria definição legal, plasmada na Resolução 237/97 do CONAMA, em seu Art. $1^{\circ}$, inciso III:

Estudos Ambientais: são todos e quaisquer estudos relativos aos aspectos ambientais relacionados à localização, instalação, operação e ampliação de uma atividade ou empreendimento, apresentado como subsídio para a análise da licença requerida, tais como: relatório ambiental, plano e projeto de controle ambiental, relatório ambiental preliminar, diagnóstico ambiental, plano de manejo, plano de recuperação de área degradada e análise preliminar de risco. Grifos nossos (CONAMA,1997)

Com vistas a divulgar o resultado do estudo ambiental de forma clara ao cidadão leigo, as informações devem ser apresentadas para discussão na audiência pública, momento em que se deve expor aos interessados, de forma clara e de fácil entendimento, o conteúdo do EIA em análise e de seu referido RIMA, para que sejam dirimidas dúvidas e recolhidas as críticas e sugestões a respeito do projeto em questão, tudo isso de acordo com o art. $1^{\circ}$ da Resolução CONAMA 009 de 03 de dezembro de 1987.

O RIMA deve ter linguagem acessível, ilustrada por mapas, cartas, quadros, gráficos e demais técnicas de comunicação visual, de modo que se possam entender as vantagens e desvantagens do projeto, bem como todas as consequências ambientais de sua implementação.

A audiência pública, de acordo com a resolução retromencionada, acontece: sempre que o órgão ambiental licenciador julgar necessário; quando houver solicitação de alguma entidade civil; por solicitação do Ministério Público; ou a pedido de 50 (cinquenta) ou mais cidadãos. Depreende-se, portanto, que a norma dá oportunidade à sociedade organizada de interferir diretamente no procedimento, mesmo que haja inércia por parte da administração pública.

Esse importante instrumento para o exercício da cidadania ambiental contribui para os necessários ajustes metodológicos e de conteúdo do EIA/RIMA, proporcionando a exposição de ideias, argumentos e sugestões de interesse da população ali representada. O EIA/RIMA deve ser disponibilizado pelo empreendedor quinze dias úteis antes da audiência pública, tempo necessário para o acesso de qualquer cidadão interessado, garantindo, assim, uma equidade nas manifestações dos atores sociais na audiência pública.

O EIA/RIMA apresentado de forma alguma deve ser considerado pronto e acabado, pois, assim, perde-se o sentido participativo da reunião tornando-se ele uma simples comunicação para uma plateia sem nenhum poder de decisão. (MILARÉ, 2007).

É importante frisar que o caráter democrático e participativo da audiência pública é garantido pelos dispositivos legais, porém, apesar dos fundamentos legais e sociais relevantes, esse mecanismo ainda tem muito em que evoluir, pois "as instituições democráticas brasileiras são ainda frágeis, eivadas da inexperiência e de açodamento" (MILARÉ, 2007 p. 389). O autor ressalta, ainda, que a audiência pública não é um comício, um plebiscito ou um "palco de torcidas 
organizadas" e deve transcorrer num quadro desejável de humanismo cívico, com pessoas habilitadas para isso, o que exige certo grau de avanço de politização quanto à solução de problemas relacionados ao bem da coletividade.

Sendo um requisito formal essencial ao licenciamento ambiental nos casos dispostos na norma, a importância desse instituto é inegável, pois, se a audiência pública solicitada não for realizada, isso será causa de anulação do processo de licenciamento. Dependendo da complexidade do projeto, do grau de impacto e da área de influência do empreendimento, podem realizar-se várias audiências públicas, sendo todas condições si ne qua non para a validação da licença ambiental que porventura venha a ser expedida, no caso de aprovação do EIA/RIMA pelo órgão licenciador competente.

No Brasil, a norma jurídica dá espaço para mobilização da sociedade, mas nem tudo funciona a contento. Num resgate histórico, Agra Filho (1993) analisou a participação popular em audiências públicas, baseado numa pesquisa que abrangeu o universo de vinte Estudos de Impactos Ambientais, concluindo que ocorre um total sentimento de frustração das pessoas envolvidas, devido a fatores como: linguagem inacessível do Relatório de Impacto Ambiental (apesar de seu objetivo legal de clareza e objetividade); prazo exíguo para conhecimento dos problemas ambientais apresentados; postura unilateral dos órgãos ambientais na defesa de suas opiniões.

Nas primeiras décadas do século XXI, o nível de participação das comunidades nas audiências públicas ainda apresenta gargalos, de acordo com diversos autores. Dentre os motivos para tais dificuldades na fase da consulta pública do EIA/RIMA, Barbieri (2007) alerta para a possibilidade desses momentos servirem para fins políticos e economicamente ilegítimos, de um lado com o objetivo de retardar o início da implantação do empreendimento, por parte de concorrentes desleais, ou, por outro lado, com o empreendedor manipulando grupos para defender um determinado projeto, sob o argumento da geração de empregos para a cidade ou a região, deixando passar ao largo as questões ambientais.

Ainda sobre a mobilização da comunidade, Granziera (2009) ressalta o fator político, que influencia positiva ou negativamente no sentido da sustentabilidade, pois a qualidade da mobilização popular depende do grau de cidadania da comunidade atingida pelos impactos do empreendimento. Assim como o nível de educação cidadã, é o grau de interação e consciência política de uma comunidade que vai determinar se as decisões tenderão mais para os aspectos econômicos empresariais ou para os interesses da coletividade atingida no sentido da sustentabilidade econômica e ambiental.

A conjuntura nacional, onde a prática ainda é relativamente incipiente com falhas de natureza estrutural e operacional nos procedimentos metodológicos dos estudos ambientais, tornam as avaliações ambientais, em sua essência, justificativas para adoção das medidas de mitigação dos impactos, sem levar em conta as particularidades do contexto ambiental em estudo, conforme Fernandes (2005). Dentre as particularidades mencionadas pelo autor estão a estrutura sócioambiental da região que sofrerá o impacto, seus usos, costumes, tradições, potenciais econômicos, níveis de empregabilidade da população para assumir os possíveis empregos que surgirão.

Por isso é tão importante o olhar atento e consciente da comunidade atingida, para fazer valer o direito de participação garantido pelo ordenamento jurídico e não se deixar levar por vantagens imediatas que no futuro possam gerar passivos socioambientais difíceis ou até mesmo impossíveis de serem revertidos. 
Afinal, conforme o art. 50 da Resolução de no 09 de 03 de dezembro de 1987 do CONAMA, a ata da(s) audiência(s) pública(s) e seus anexos servirão de base, juntamente com o RIMA, para a análise e o parecer final do licenciador, sendo elementos decisórios na aprovação ou não do projeto.

Diante desse contexto, apresenta-se a seguir a percepção de uma parcela de atores sociais legitimada para participar de audiências públicas sobre os temas abordados neste estudo.

\section{A PERCEPÇÃO DOS ATORES SOCIAIS.}

Sobre a importância do licenciamento ambiental os atores sociais reconheceram que instrumento existe para cumprir a lei e acham importante que ele exista tal. Porém chamam a atenção para a atuação dos órgãos ambientais na área, pois a percepção do grupo é que após o licenciamento ser aprovado, não existe fiscalização ambiental na região.

A maioria dos informantes presentes já participou de Audiências Públicas Ambientais ocorridas na região, porém reconhece que tais momentos de interação com a comunidade são escassos e insuficientes. Foi ressaltado que as audiências públicas esclarecem algumas dúvidas, porém geram outras, que terminam por não serem respondidas, uma vez que não há um retorno para a população sobre os resultados e as sugestões acatadas.

Em relação à geração de empregos para a região, os entrevistados reconhecem que são poucos os empregos gerados e sazonais. Sobre o assunto segurança pública, integrantes do grupo ressaltaram o aumento da violência devido às drogas, e que o dinheiro do petróleo arrecadado pelo município através dos royalties não contribuiu para a melhoria da segurança da região. Também não há, por parte do grupo, a percepção de melhoria nos outros serviços essenciais, como educação e saúde, contando a comunidade com os mesmos precários equipamentos sociais.

O grupo reconhece a importância da participação da comunidade nas audiências públicas e também o baixo índice de envolvimento da população, fato reconhecido por todos os integrantes. Foram apresentadas como prováveis causas o fato de as audiências serem burocráticas e também a falta de oitiva dos segmentos da sociedade que serão atingidos pelos possíveis impactos da extração de petróleo, durante a feitura dos estudos ambientais. Em relação aos conhecimentos tradicionais a respeito do tema os entrevistados reconhecem que não foram levados em conta, nem ao menos foram citados na audiência pública. Reclamam, por exemplo, de as plataformas de perfuração marítima terem sido instaladas em locais onde existiam atividades pesqueiras, que passaram a ser proibidas por questões de segurança. Desta forma, segundo eles, onde existem mais peixes agora é proibido pescar.

A impressão geral colhida dos entrevistados é que a população da região é até chamada para as audiências públicas, onde são ouvidas suas sugestões, mas o retorno aos seus questionamentos não é a práxis. Relataram, outrossim, que é comum, um tempo depois, essa mesma população assistir a implantação dos empreendimentos já licenciados, sem saber se suas arguições foram levadas em consideração, conforme prescreve a lei.

\section{CONSIDERAÇÕES FINAIS}

A Constituição Federal Brasileira de 1988 propõe um sistema de responsabilidades compartilhadas. Para isso, o envolvimento da comunidade através de mecanismos de participação popular efetiva, constitui-se em uma premissa para efetivação do comando principiológico constitucional. 
Porém os baixos níveis de educação, no Brasil, a falta de boa vontade dos governantes e o desconhecimento dos mecanismos das instituições políticas pela maioria da população geram fragilidades na realidade da prática democrática. A causa ambiental exige um aprofundamento da democracia e do exercício da cidadania, que necessita da valorização das instituições democráticas cujo importante vetor é o acesso à educação de qualidade (LEITE e AYALA, 2004).

No entanto de nada adianta a responsabilização compartilhada se não houver preparo e amadurecimento da cidadania, para que a comunidade não se transforme em massa de manobra dos interesses contrários ao desenvolvimento sustentável. Por outro lado, mesmo quando a sociedade quer participar, a vontade esbarra nas dificuldades de diálogo, refletidas principalmente na falta de retorno aos seus questionamentos por ocasião das audiências públicas.

Assim, a realidade prática distancia-se da construção da racionalidade ambiental, pois, para que as comunidades exerçam seu direito/dever de proteger o meio ambiente, é necessário o bom funcionamento da máquina pública, além de incentivos à educação para o exercício da cidadania contemplando os diversos saberes e anseios das comunidades. (LEFF,2009)

A partir das percepções colhidas do grupo de atores sociais apresentadas neste trabalho, percebe-se que os conhecimentos tradicionais dos moradores da região são ignorados nos estudos ambientais, demonstrando o viés calcado no paradigma científico cartesiano dominante. Assim, devido às falhas na implantação da verdadeira democracia ambiental, o princípio da responsabilização compartilhada é mitigado pelas deficiências demonstradas a partir na entrevista do grupo focal exposta neste trabalho.

A norma jurídica pode ser um elemento chave para a construção da racionalidade ambiental. Porém ela só se torna eficiente quando a sociedade amadurece no exercício da cidadania; caso contrário, torna-se letra morta.

O desafio do exercício da gestão pública ambiental de acordo com os critérios da racionalidade ambiental encontra no Brasil, país de biodiversidade e riqueza cultural peculiares, um território fértil para sua aplicação, uma vez que a tolerância entre as diversas culturas que formaram esta nação é um exemplo para o mundo, porém ainda se vive o processo de amadurecimento do exercício efetivo da democracia.

Os tempos mudaram, e a sociedade brasileira do início século XXI caminha, mesmo com as dificuldades e contrastes de um país em desenvolvimento, para um aprofundamento das práticas democráticas, decorrente da elevação dos níveis de educação, ainda que de forma mais lenta que desejável. Com mais educação, aprimora-se a busca do desenvolvimento includente e sustentável (SACHS, 2008). E, assim, se amplia a consciência da cidadania; afinal, "todo poder emana do povo, que o exerce por meio de representantes eleitos ou diretamente, nos termos desta Constituição" (BRASIL,1988).

Resta à população, enquanto parte interessada, utilizar os instrumentos democráticos dispostos na Carta Magna para preservar seu meio ambiente para as presentes e futuras gerações.

\section{REFERÊNCIAS BIBLIOGRÁFICAS}

1. AGRA FILHO, Severino Soares. Os estudos de impactos ambientais no Brasil: uma análise de sua efetividade. Dissertação de Mestrado. Rio de Janeiro: Universidade Federal, 1993. 
2. AYALA, Patryck de Araújo. Devido processo ambiental e o direito fundamental ao meio ambiente. Rio de Janeiro: Lumen Juris, 2011.

3. ANTUNES, Paulo de Bessa. Política nacional do meio ambiente. Comentários à Lei 6938/81. Rio de Janeiro: Lumen Juris, 2005.

4. BARBIERI, José Carlos. Gestão ambiental empresarial. 2. ed. atual. e ampliada. São Paulo: Saraiva 2007.

5. BRASIL. Constituição (1988). Constituição da República Federativa do

6. Brasil. Lex: Constituição Federal, Coletânea de Legislação de Direito Ambiental, São Paulo, 5.ed.rev.,atual.,ampl.Editora Revista dos Tribunais, 2006.

7. . Lei n. 6.938, de 31 de agosto de 1981. Dispõe sobre a Política

8. Nacional do Meio Ambiente. disponível em http://www.planalto.gov.br/ccivil_03/Leis/L6938.htm . Acesso em 20 de abril de 2011

9. CONAMA. Conselho Nacional do Meio ambiente. Resolução n09 de 03 de dezembro de 1987. Disponível em http://www.mma.gov.br/port/conama/res/res87/res0987.html Acesso em 20 de abril de 2011.

10. FERNANDES, Paulo Victor. Impacto ambiental: doutrina e jurisprudência. São Paulo: Ed. Revista dos Tribunais, 2005.

11. FREIRIA, Rafael Costa. Direito, gestão e políticas públicas ambientais. São Paulo: Editora SENAC, 2011.

12. FIORILLO, Celso Antônio Pacheco; MORITA, Dione Mari; FERREIRA, Paulo Licenciamento ambiental. São Paulo: Saraiva, 2011.

13. GRANZIERA, Maria Luiza Machado. Direito ambiental. São Paulo: Editora Atlas, 2009

14. LEFF, Enrique. Epistemologia ambiental. São Paulo: Cortez, 2007.

15. . Saber ambiental. Rio de Janeiro: Ed. Vozes 2009.

16. LEITE, José Rubens Morato e AYALA, Patrick de Araújo. Direito Ambiental na Sociedade de Risco. 2 ed. Rio de Janeiro: Forense Universitária, 2004.

17. MILARÉ, Edis. Direito do ambiente: a gestão ambiental em foco. Doutrina Jurisprudência e Glossário. 5 a edição. São Paulo: Editora Revista dos Tribunais, 2007.

18. MILARÉ, Édis e BENJAMIN, Antonio H. V. Estudo prévio de impacto ambiental. Teoria, prática e legislação. São Paulo, Editora Revista dos Tribunais, 1993.

19. MINAYO, Maria Cecília de Souza. O desafio do conhecimento: pesquisa qualitativa em saúde. 8. ed. São Paulo: Hucitec, 2004.

20. SÁNCHEZ, Luiz Henrique. Avaliação de Impacto Ambiental: conceitos e métodos. São Paulo: Oficina de Textos, 2006.

21. SACHS, Ignacy. Desenvolvimento: includente, sustentável e sustentável. Rio de Janeiro: Garamond, 2008. 